\title{
Efficient dye-removal via Ni-decorated graphene oxide-carbon
}

\section{nanotube nanocomposites}

Chenxi Hu ${ }^{\mathrm{a}}$, Anh Thi Le ${ }^{\mathrm{b}}$, Swee Yong Pung ${ }^{\mathrm{b}}$, Lee Stevens ${ }^{\mathrm{c}}$, Nigel Neate ${ }^{\mathrm{a}}$, Xianghui Hou ${ }^{\mathrm{a}}$, David

Grant $^{\mathrm{a}}$, Fang $\mathrm{Xu}^{\mathrm{a}, *}$

a. Advanced Materials Research Group, Faculty of Engineering, University of Nottingham, NG7 2RD, UK

b. School of Materials and Mineral Resources Engineering, Universiti Sains Malaysia, Engineering Campus, 14300 Nibong Tebal, Pulau Pinang, Malaysia

c. Low Carbon Energy and Resources Technologies Research Group, Faculty of Engineering, University of Nottingham, University Park, Nottingham, NG7 2RD, UK

\begin{abstract}
The nickel nanoparticles decorated graphene oxide-carbon nanotubes nanocomposite has been prepared through a novel molecular-level-mixing method followed by a freeze-drying and subsequent reduction process. The resulting products showed a well-dispersed 3D structure and demonstrated excellent performance in removing Rhodamine $\mathrm{B}(\mathrm{RhB})$ from the aqueous solution through a synergistic effect of physical adsorption and photo-degradation. The physical adsorption of RhB by this nanocomposite followed the pseudo-second-order and could be ascribed to its high surface area. The nanocomposite containing $30 \mathrm{wt} . \%$ of Ni exhibited the highest removal capacity of ca. $41.5 \mathrm{mg} \mathrm{g}$ -

${ }^{1}$ in $5 \mathrm{ppm} \mathrm{RhB}$ solution. Meanwhile, because of the ferromagnetism of Ni nanoparticles coated, the nanocomposite could be easily collected and recycled after the removal of dye via magnetic separation. Thus, the nanocomposite have demonstrated great potentials as an efficient adsorbent with good photocatalytic performance for removing organic dyes from wastewater.
\end{abstract}

\section{Keywords:}

GO-CNT nanocomposites, Ni nanoparticles decoration, Mesoporous structure, RhB removal, Easy collection.

\footnotetext{
*E-mail: Fang.Xu@nottingham.ac.uk (Fang Xu), Phone: +44 1158467019.
} 


\section{Introduction}

Environmental problem is one of the most important issues to our human beings, and water pollution is increasingly a problem that needs to be dealt with by improving techniques. Textile, paper mills and cosmetics industries are the major producers for wastewater containing dyes and pigments [1]. These coloured pollutants, which are normally difficult to decompose due to their chemical stability, are mostly regarded as toxic and potentially carcinogenic. Therefore, to develop economic and efficient approaches for the removal of these pollutants from wastewater (i.e. physical adsorption, chemical precipitation and oxidation and membrane filtration [2-4]) are of great importance. As one of the most commonly used dyes nowadays, rhodamine $\mathrm{B}(\mathrm{RhB})$ has been widely reported as an example in dye removal investigations [5]. Adsorption and filtration are widely used to remove a large range of effluents, due to their easy operation, however, they only transfer pollutants from water to another phase which causes secondary pollutions. As an eco-technique emerged recently, photo-degradation has shown potentials in dealing with effluents, because upon removing organic compounds this technique can transform harmful molecules into environment-friendly by-products [6]. The key is to explore low-cost and easy operation photocatalyst and realise the photo-degradation process with high efficiency.

Carbon materials, based on a large array of allotropes such as carbon nanotubes (CNTs) and graphene, have been investigated in water purification due to the excellent adsorption properties originating from their large surface areas [7, 8]. In particular, a three-dimensional hybrid nanostructure made of CNTs and graphene or graphene oxides (GOs) can further enhance surface area [9-11] and provide affluent contact surface and reaction sites for the removal of pollutants. A self-assembled graphene-CNT hybrid prepared by Ai et al. showed a specific surface area of $78.9 \mathrm{~m}^{2} \mathrm{~g}^{-1}$, with a good absorbing ability with methylene blue [12]. In addition, previous research has also witnessed the electron transfer in carbon materials, the 
sp2 structure in carbon material has been proved to be capable of stringing and shuttling electrons, $[12,13]$. Meanwhile, Jiang et al. has also reported that electrons can be excited from $\mathrm{RhB}$ and then transferred through graphene and CNTs which slowed down the recombination between electrons and $\mathrm{RhB}^{\cdot+}[14]$. Thus, the graphene-CNT structure exhibits great potentials in photo-catalysis applications.

Traditional semiconductors (i.e. $\mathrm{ZnO}$ [15], $\mathrm{TiO}_{2}$ [16], $\mathrm{CdS}$ [17]), transition metal oxide $\left(\mathrm{Fe}_{2} \mathrm{O}_{3}\right.$ [18], $\mathrm{WO}_{3}[19]$ and $\mathrm{SnO}_{2}$ [20]), the noble metal nanoparticles [e.g. Au [21], Ag [22], $\mathrm{Ni}[2,23]]$ and ferrites $\left(\mathrm{NiFe}_{2} \mathrm{O}_{4}, \mathrm{CoFe}_{2} \mathrm{O}_{4}\right.$ and $\left.\mathrm{MnFe}_{2} \mathrm{O}_{4}\right)$ [24] have been employed as photocatalysts to remove coloured dyes from water. Among them, noble metal-based composites, especially Ni-based material, have attracted increasing attention. The Ni nanoparticle shows potentials in application due to its lower cost when comparing with $\mathrm{Au}$ or $\mathrm{Ag}$. The ferromagnetism of $\mathrm{Ni}$ also made it more convenient to be collected after reaction and reuse when compared with traditional materials $[25,26]$. In addition, nanoparticles can also play an important role as spacers in reducing the agglomeration of graphene or CNTs when uniformly disperse among them. Therefore, a combination of such materials has become possible route for preparing advanced materials in dealing with dyes. Typical preparation routes for $\mathrm{Ni}-\mathrm{C}$ materials are: cation exchange process in order to deposit $\mathrm{Ni}$ on reduced-GO (RGO) sheet [27], chemical vapour deposition method to prepare Ni/graphene nanocomposites [28] and hydrothermal methods [29], as well as in hydrazine hydrate solution under ultrasound conditions [2]. However, the relatively long and complex preparation process of these procedures and/or high temperature normally hinder the development.

In the work presented here, a novel molecular-level-mixing (MLM) process, which was first developed by Cha and co-workers [30], with subsequent freeze-drying and reduction process has been developed to prepare uniformly Ni nanoparticles decorating GO-CNT (GNT) 
nanocomposites. The well-dispersed $\mathrm{Ni}$ nanoparticles on 3-dimensional (3D) GNT nanostructure exhibited great potential as a photo-catalyst, as verified by the degradation tests carried out on $\mathrm{RhB}$.

\section{Experimental}

\subsection{Materials}

Graphite, carbon nanotubes (MWCNTs, outer diameter: 6-9 nm, length: $5 \mu \mathrm{m}$ ), nickel acetate $\left[\mathrm{Ni}\left(\mathrm{CH}_{3} \mathrm{COO}\right)_{2}\right]$, sulfuric acid $\left(\mathrm{H}_{2} \mathrm{SO}_{4}, 98 \%\right)$, sodium nitrate $\left(\mathrm{NaNO}_{3}\right)$, potassium permanganate $\left(\mathrm{KMnO}_{4}\right), \mathrm{RhB}$ and hydrogen peroxide $\left(\mathrm{H}_{2} \mathrm{O}_{2}\right)$ were purchased from SigmaAldrich, while nitric acid $\left(\mathrm{HNO}_{3}\right)$ was purchased from Fisher Scientific. Liquid $\mathrm{N}_{2}$, pure $\mathrm{Ar}$ gas and $\mathrm{Ar} / \mathrm{H}_{2}$ mixed gas $\left(5 \% \mathrm{H}_{2}+95 \%\right.$ Ar) were supplied by BOC Gas Cylinders.

\subsection{Pre-treatment of CNTs and preparation of GOs}

$0.5 \mathrm{~g}$ as-received CNTs were placed into a reaction flask, and $10 \mathrm{~mL} \mathrm{HNO}_{3}(70 \%)$ was gently poured inside, followed by slow addition of $5 \mathrm{~mL} \mathrm{H}_{2} \mathrm{SO}_{4}(98 \%)$ for further modification. The flask was then connected to a reflux system and gradually heated up to $130^{\circ} \mathrm{C}$ in an oil bath. After boiling for $25 \mathrm{~min}$, the acid-treated CNTs were subject to further filtering and rinsing several times with distilled water, and then dried overnight in a vacuum oven at $60^{\circ} \mathrm{C}$. The preparation of graphene oxides, GOs, was based on the modified Hummers' method [31].

\subsection{Preparation of GNTs and Ni/GNTs nanocomposites}

The CNT and GO powders (with a weight ratio of 1:1) were dispersed in water with a concentration of $0.4 \mathrm{mg} \mathrm{mL}^{-1}$ under sonication for one hour in order to achieve a suspension. Similar to GNTs, the Ni/GNTs nanocomposites were prepared based on the suspension of GNTs. After the dispersion of GO and CNTs, different concentrations of nickel acetate (with 
a weight ratio of $\mathrm{C}: \mathrm{Ni}$ from $1: 9,3: 7,5: 5$, to $7: 3$ ) were then dissolved in $50 \mathrm{~mL}$ water under stirring. GO and CNT mixed suspension was then added to the well-dissolved nickel acetate solution and magnetically stirred for another $2 \mathrm{~h}$. After that, the suspensions of GNTs and $\mathrm{Ni} / \mathrm{GNTs}$ were quickly frozen by liquid $\mathrm{N}_{2}$ and then freeze-dried in a freeze dryer at $-55^{\circ} \mathrm{C}$ and 0.024 mBar. The freeze-dried GNT nanostructures and Ni precursors were subsequently reduced under $\mathrm{H}_{2} / \mathrm{Ar}$ atmosphere at $400^{\circ} \mathrm{C}$ in a tube furnace for $2 \mathrm{~h}$. The as-prepared samples were named based on their calculated carbon ratio from FG10Ni90 to FG70Ni30 as freezedried GNT Ni nanocomposites (i.e. FG10Ni90 refers to $10 \mathrm{wt} . \%$ of carbon content and $90 \mathrm{wt} . \%$ of $\mathrm{Ni}$ content). The pure Ni sample was also prepared as a reference sample following the same method, without the addition of GO-CNT mixture.

\subsection{Characterisation}

X-ray powder diffraction (XRD) was conducted on a Bruker D8 Advance system (operated at $40 \mathrm{kV}$ and $35 \mathrm{~mA}$ ) using $\mathrm{Cu} \mathrm{K-} \alpha$ radiation as the $\mathrm{X}$-Ray source, between $10-80^{\circ} 2 \theta$ range at a scanning step of $0.01^{\circ}$. Morphologies of the final products were investigated using a JEOL 7100F Field Emission Gun Scanning Electron Microscopy (FEG-SEM) system with an accelerating voltage of $15 \mathrm{kV}$ and a JEOL 2100+ Transmission Electron Microscopy (TEM) with a working voltage of $200 \mathrm{kV}$. The TEM sample was prepared by dispersing the asprepared powders in ethanol under sonication and then dropping onto holey carbon TEM grids. X-ray photoelectron spectroscopy (XPS) was carried out on a VG ESCALab Mark II spectrometer machine using $\mathrm{Al} \mathrm{K}-\alpha \mathrm{X}$-ray as an excitation source with a wavelength of $1486.6 \mathrm{eV}$. It was performed under a condition of anode voltage of $12 \mathrm{kV}$ and an emission current of $20 \mathrm{~mA}$. A simultaneous thermogravimetric experiment was performed using TA Q600 SDT, and all the samples were measured from 50 to $800{ }^{\circ} \mathrm{C}$ in air with a ramp rate of $10{ }^{\circ} \mathrm{C} \min ^{-1}$. BET specific surface areas of the samples were measured by Micromeritics ASAP 2420 accelerated surface area and porosimetry system and was calculated from a 
relative pressure range of 0.05 to 0.20 on an $\mathrm{N}_{2}$ adsorption isotherm at $-196^{\circ} \mathrm{C}$ giving positive BET ' $C$ ' parameters. Pore volume and size distribution were acquired from the isotherms using NLDFT on carbon slit pore model. The freeze-drying approach was carried out with a Labconco FreeZone 76705 freeze dry system at a sublimation condition at $-55^{\circ} \mathrm{C}$ and 0.024 mBar.

\subsection{Measurement of photocatalytic properties.}

The RhB removal performance of the as-prepared products was evaluated under the dark and under UV irradiation ( $360 \mathrm{~W}, 254 \mathrm{~nm}$ ). The results were recorded using Carry $50 \mathrm{UV}$ Visible spectrophotometer, and the absorbance was measured from $400 \mathrm{~nm}$ to $700 \mathrm{~nm}$ at a step of 1 $\mathrm{nm}$ with a scan speed of $600 \mathrm{~nm} \mathrm{~min}^{-1}$. First, $250 \mathrm{~mL} 5 \mathrm{ppm} \mathrm{RhB}$ solution was stirred in dark, and $25 \mathrm{mg}$ obtained FGNi sample was dispersed in the solution. Then, the physical adsorption of RhB dye onto the samples within 120 min was assessed, and the absorbance peak of RhB dye was obtained with a 15 min interval using the UV-VIS spectrometer. To investigate the photocatalytic property, the mixed suspension was initially stirred in the dark for $60 \mathrm{~min}$ to allow for adsorption equilibrium. Then, it was transferred and irradiated under a UV lamp and the absorbance peak of RhB was also recorded every $15 \mathrm{~min}$ by the UV-VIS spectrometer. The RhB solution showed a maximum absorb peak at $c a .554 .5 \mathrm{~nm}$, and this absorbance corresponded to the concentration of $\mathrm{RhB}$ dye [32]. The photo-degradation efficiency (PE) was calculated according to

$$
P E(\%)=\left(A_{0}-\mathrm{A}_{t}\right) / \mathrm{A}_{0} \times 100 \%
$$

where $A_{0}$ and $A_{t}$ are the UV-VIS absorbance intensity of the RhB dye solution at the initial and a given time interval of irradiation, respectively. To explore the adsorption kinetic of asprepared samples, $25 \mathrm{mg}$ FG30Ni70 nanocomposites were dispersed in $250 \mathrm{~mL} 5 \mathrm{ppm}$ RhB solution in the dark, and the absorbance was recorded from 5 min to 10, 20, 30, 45, 60 and 90 
min. The scavenger study of FG30Ni70 nanocomposites was carried out following the procedure below. Several kinds of reactive species, e.g. hydroxyl $\left(\mathrm{OH}^{\prime}\right)$ free radicals, and superoxide anion $\left(\mathrm{O}^{2 \cdot-}\right)$ free radicals, could be generated to react with dyes. To further confirm the photo-degradation mechanism, if there was any, a scavenger experiment was introduced to confirm such reactions. Specifically, different scavengers, for example, methanol for $\mathrm{OH}^{\cdot}$ free radicals, potassium iodide (PI) for holes $\left(\mathrm{h}^{+}\right)$free radicals and $\mathrm{p}$ benzoquinone $(\mathrm{BQ})$ for $\mathrm{O}_{2}{ }^{\bullet-}$ free radicals, were added into $\mathrm{RhB}$ solution with as-prepared FG30Ni70 nanocomposites after dark equilibrium. The removal efficiency of RhB solution by FG30Ni70 nanocomposites would be greatly suppressed if the targeted reactive species was responsible for the degradation of RhB dye. After stirring in the dark for $60 \mathrm{~min}$, the mixtures were transferred under UV irradiation and recorded the final efficiency through a $\mathrm{UV}-\mathrm{Vis}$ spectrometer.

\section{Results and discussion}

\subsection{Structure and morphology characterisation}

Fig. 1 displays the XRD patterns of pure Ni and FGNi nanocomposites with different ratio of carbon content. As expected, diffraction peaks at $44.5^{\circ}, 51.8^{\circ}$ and $76.4^{\circ} 2 \theta$ are observed in all the Ni containing samples (Fig. 1a-e), matching the (111), (200) and (220) planes of standard metallic Ni (ICDD PDF No. 00-04-0850). The intensities of the diffraction peaks decrease with the increase of the carbon content in the samples. A broad peak ranging from $20-30^{\circ}$ can be attributed to the existence of carbon materials [33, 34], and becomes more prominent with the increase of carbon content and the FG70Ni30 sample shows the highest intensity (Fig. 1e). Apart from the Ni and carbon signals, no other peaks are detected. This result confirms that the products were completely reduced to Ni phase and the GNT content was preserved under the treatment at $400^{\circ} \mathrm{C}$ for $2 \mathrm{~h}$ in $\mathrm{Ar} / \mathrm{H}_{2}$ atmosphere. 


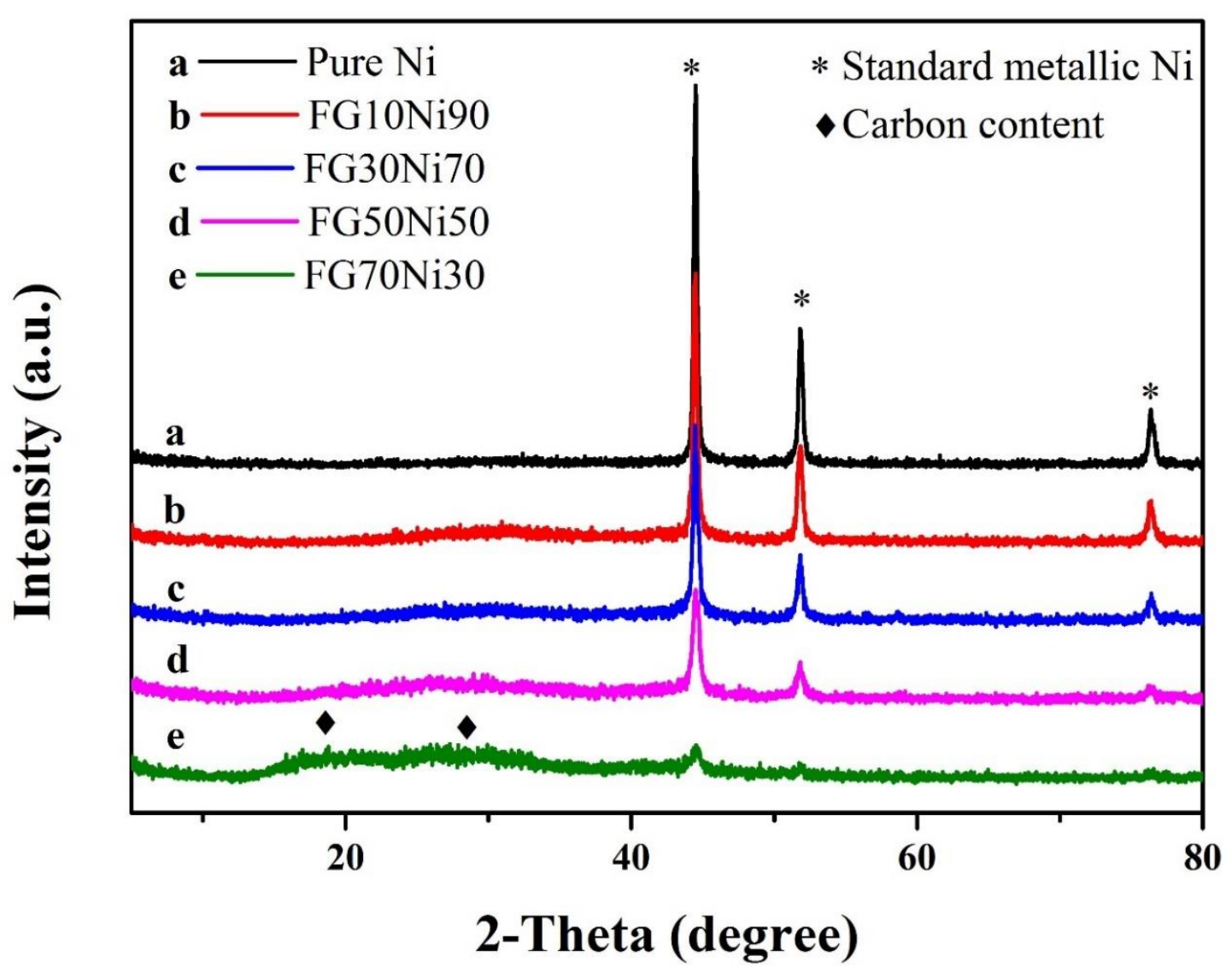

Fig. 1 XRD patterns of FGNi nanocomposites and pure Ni.

To further confirm the composition of the as-prepared nanocomposite, the $\mathrm{Ni} / \mathrm{C}$ ratio of each product has been studied based on TGA results (Fig. S1). In pure Ni sample (Fig. S1a), the weight shows an increase after $200^{\circ} \mathrm{C}$ and reaches a final percentage of $125 \%$ then remains stable after $600^{\circ} \mathrm{C}$, indicating the $\mathrm{Ni}$ phase was oxidised into $\mathrm{NiO}$ phase in air. For the rest of the carbon containing samples, the trend of their weight change varies (Fig. S1b-e). All the weight of each sample shows an initial increase after $200^{\circ} \mathrm{C}$ which can also be ascribed to the oxidation of $\mathrm{Ni}$ in air. After that, the weight decrease becomes more pronounced with the increase of carbon content except for the FG10Ni90 sample, due to the oxidation of carbon in air. Specifically, the FG10Ni90 sample still displays a weight increase but less than the pure Ni sample which is caused by the weight loss of carbon content, and the calculated carbon percentage of the FG10Ni90 sample from TGA results is $12.5 \mathrm{wt}-\%$ of carbon content. With the increase of carbon content, the calculated carbon percentage of each nanocomposite from 
TGA results is 24.6 wt- $\%$ of carbon content for FG30Ni70, 47.8 wt- $\%$ for FG50Ni50 and 64.8 wt- $\%$ for FG70Ni30. The $\mathrm{Ni} / \mathrm{C}$ ratio in all FGNi composites could be confirmed similarly to the designed proportion in the sample preparation stage.

The $\mathrm{N}_{2}$ sorption isotherms which are displayed in Fig. 2 show a type IV isotherm feature for all products, with $\mathrm{H} 2$ hysteresis loop, demonstrating the mesoporous structural feature of all samples [35]. A bar chart in Fig. 2b summarises the BET surface area of each sample. Against $9.01 \mathrm{~m}^{2} \mathrm{~g}^{-1}$ for pure $\mathrm{Ni}$, the surface area has increased to $31.8 \mathrm{~m}^{2} \mathrm{~g}^{-1}$ for FG10Ni90 nanocomposites, $71.7 \mathrm{~m}^{2} \mathrm{~g}^{-1}$ for FG30Ni70 composites, $82.7 \mathrm{~m}^{2} \mathrm{~g}^{-1}$ for FG50Ni50 composites and $175.4 \mathrm{~m}^{2} \mathrm{~g}^{-1}$ for FG70Ni30 composites. Meanwhile, the obtained surface areas of pure GO $\left(119.4 \mathrm{~m}^{2} \mathrm{~g}^{-1}\right)$ and GNT $\left(199.9 \mathrm{~m}^{2} \mathrm{~g}^{-1}\right)$ are displayed in Fig. S3c. it can be found that the introduction of CNTs effectively improves the surface area of GOs. Although the coating of Ni nanoparticles decreases the surface area, it is noted that the surface areas are increased when the GNT contents were introduced and raised with these carbon contents. The significant surface area increase of FG70Ni30 sample can be ascribed to the large volume of carbon component in the sample $(91.7$ vol.\%). In the pore volume and size distribution histogram shown in Fig. S2, the total pore volume (up to $100 \mathrm{~nm}$ ) was seen to increase with higher carbon content. In addition, the pore diameter ranging from 2-50 nm is dominant for all samples, which also further confirmed the mesoporous structures of the products. Thus, a mesoporous structure with a high surface area has been obtained in the FGNi nanocomposites with different carbon contents. 

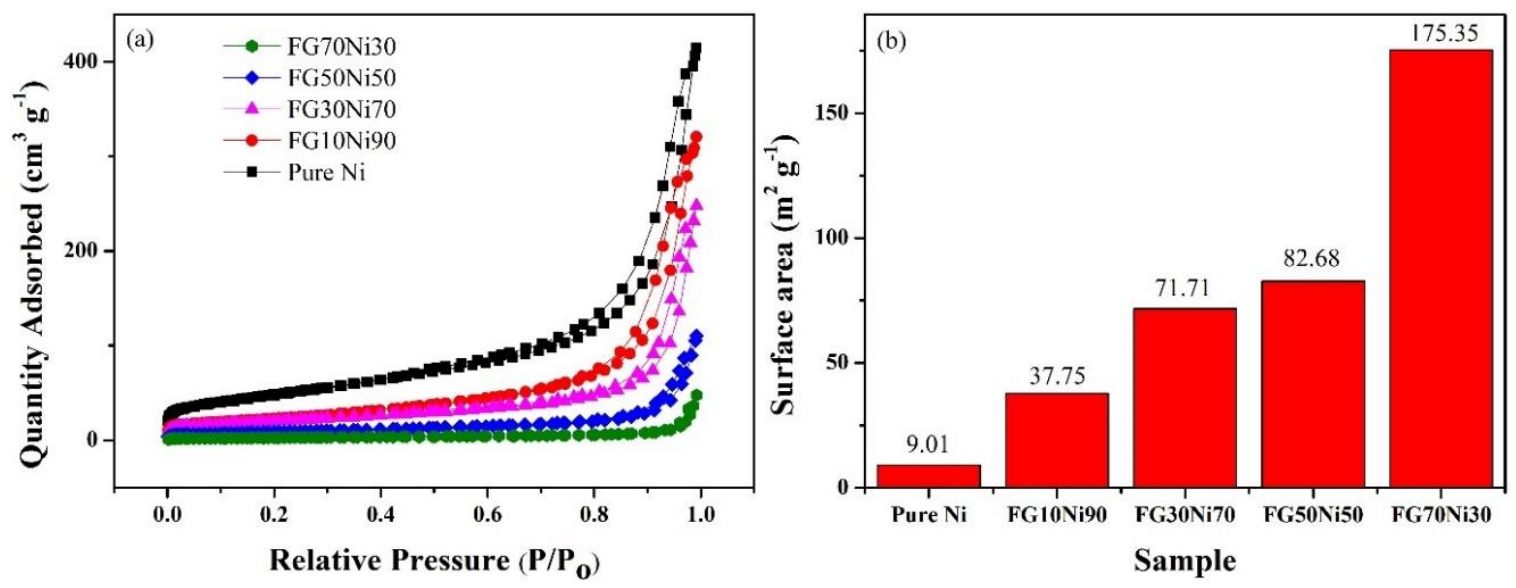

Fig. 2 (a) $\mathrm{N}_{2}$ adsorption - desorption isotherm curves of all samples and (b) calculated BET surface area of each composition.

Typical secondary electron SEM and bright field TEM images of prepared nanocomposites are displayed in Fig. 3 and Fig. S 3 and 4. For pure GO and GNTs (Fig. S3 a and b), a welldispersed graphene-layer like structure could be clearly observed in both samples, with no obvious stacks or agglomeration that are normally associated with graphene-based materials [36]. Meanwhile, CNTs are recognised sitting on the surface of graphene layers (Fig. S3b), due to the $\pi-\pi$ interactions between carbon atoms. These results confirm that the freezedrying method which was adopted in preparing GNTs has successfully prepared a welldispersed structure. After adding $\mathrm{Ni}$ acetate as precursors, the 3D graphitic structures of sample FGNi can still be observed (Fig. 3a and b), with Ni nanoparticles uniformly dispersed on the surface of GNTs. In the TEM image of FG30Ni70 sample (Fig. 3c), graphene and CNTs could be easily detected as lighter features in the bright field images, whilst Ni nanoparticles on the surface of both graphene and CNTs appeared dark, and the particle size is around $50 \mathrm{~nm}$. The insert image of Fig. 3c displays the selected area electron diffraction (SEAD) patterns and clearly indicates the Ni (111), (200), (220) and (311) planes. At higher magnification (Fig. 3d), clear morphology of CNTs can be found and Ni nanoparticles were successfully coated on them. The CNTs also can be confirmed as multi-wall tubes. For other Ni containing samples (Fig. S4), it can be found that the Ni particles $c a .100 \mathrm{~nm}$ in size were obtained after the reduction process in pure Ni sample (Fig. S4 a and b). The particles are 
much bigger than the ones coated on GNTs which indicates that the introduction of GNT could effectively restrict the growth of Ni particles when particles nucleated on GNTs. The agglomeration of Ni particles and larger particle sizes (Fig. S4 a and b) compared with FGNi have also explained the lowest measured surface area and pore volume in pure $\mathrm{Ni}$ sample (Fig. 2).
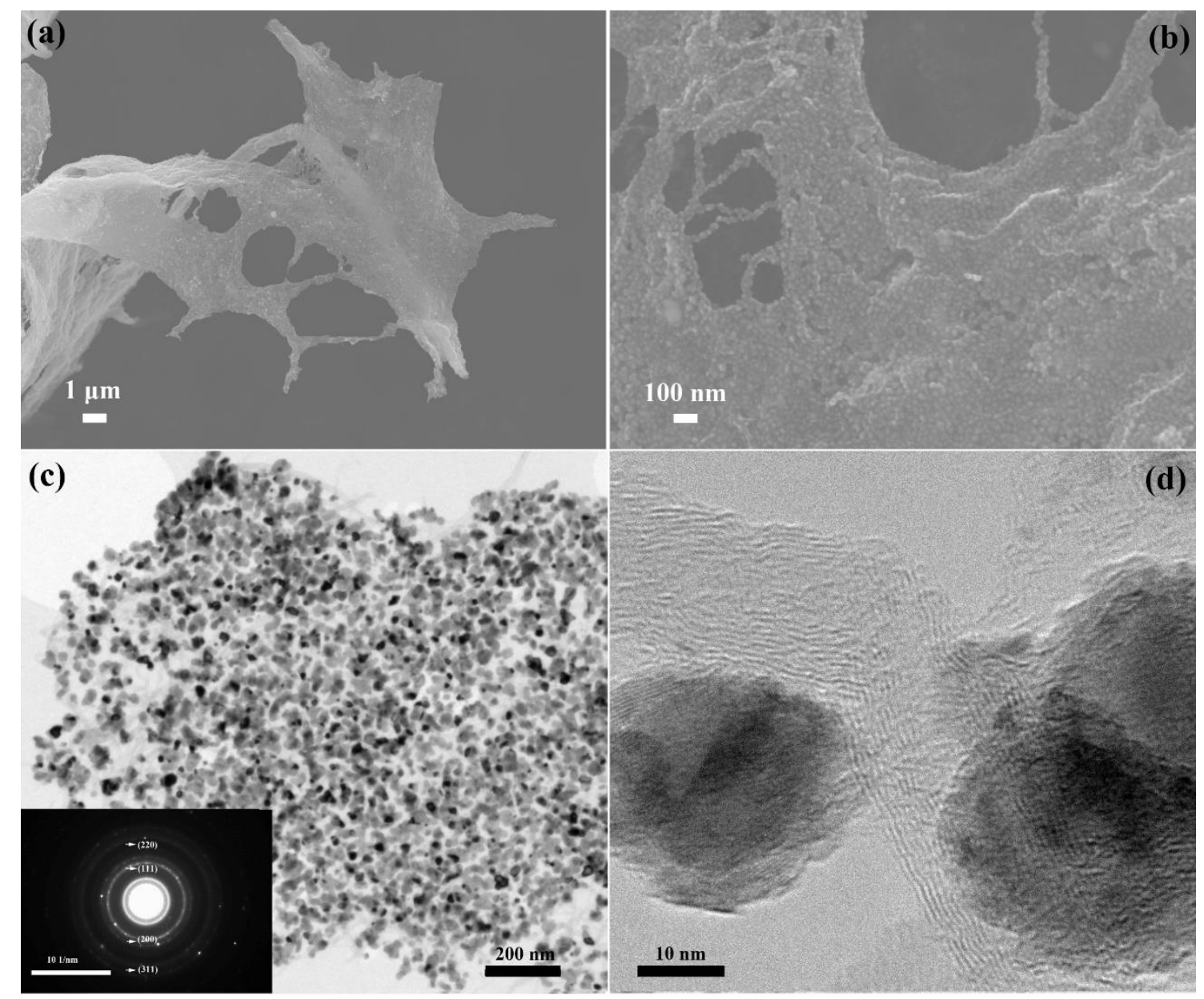

Fig. 3 SEM images (a and b) and TEM images (c and d) of FG30Ni70 nanocomposites, the insert image of Fig $3 \mathrm{c}$ is the electron diffraction (SEAD) patterns.

The XPS spectra of pure GO, pure GNT and FGNi nanocomposites are shown in Fig. 4. FG30Ni70 sample is representing FGNi nanocomposites as all FGNi samples showed similar XPS signals. From the XPS survey scan (Fig. 4a), the peaks of $\mathrm{C} 1 \mathrm{~s}$ and $\mathrm{O} 1 \mathrm{~s}$ are observed for all three samples, demonstrating the existence of $\mathrm{C}$ and $\mathrm{O}$. The $\mathrm{Ni} 2 \mathrm{p}$ peaks appear in FG30Ni70 sample, showing the presence of Ni element. For the prepared GO samples (Fig. 
$4 \mathrm{~b})$, the $\mathrm{C}$ 1s spectrum could be deconvoluted into three peaks, the $\mathrm{sp}^{2}$ hybridized $\mathrm{C}$ (C-C and $\mathrm{C}=\mathrm{C}$ ) component at $284.0 \mathrm{eV}$ [37], the $\mathrm{C}-\mathrm{O}$ which corresponds to the hydroxyl and epoxy groups at $286.3 \mathrm{eV}$, and the $\mathrm{O}=\mathrm{C}-\mathrm{OH}$ groups at $288.0 \mathrm{eV}$ [38]. The characteristic peaks of $\mathrm{O}$ containing components confirm that the functional groups are successfully attached onto the graphene layers during the preparation of GOs. The existence of such O-containing groups could not only prevent the agglomeration of graphene layers in solutions due to the electrostatic repulsion but also provide suitable sites for metal ions nucleation. It is interesting to note that the amount of C-O components in both GNT and FGNi samples has decreased compared with GO sample. The decrease of O-containing functional groups can be ascribed to the reduction process under $\mathrm{H}_{2}$ atmosphere during the preparation of GNTs and FGNi nanocomposites. Meanwhile, more deconvoluted peaks can be observed in both samples, the C-O (ether bonds) which corresponded to the hydroxyl groups at $286.3 \mathrm{eV}$, the $\mathrm{C}=\mathrm{O}$ groups (ketone bonds) at $288.9 \mathrm{eV}$ and the sp2 hybrid orbit of benzene plane at $290.8 \mathrm{eV}$ [37, 39], which also can be ascribed to the reduction process. In addition, the main $\mathrm{C}$ peaks in both GNT and FG30Ni70 samples become the $\mathrm{sp}^{2}$ hybridized C (at around $284.0 \mathrm{eV}$ ) and defectcontaining $\mathrm{sp}^{2}$ hybridized $\mathrm{C}$ (at around $285.0 \mathrm{eV}$ ). This result indicates that more $\mathrm{C}$ defects were obtained as a result of the reduction process in the preparation procedures [40, 41]. Fig. 4e shows the deconvoluted $\mathrm{Ni} 2 \mathrm{p}_{3 / 2}$ and $\mathrm{Ni} 2 \mathrm{p}_{1 / 2}$ spectra. The peaks at 853.3 and $870.5 \mathrm{eV}$ correspond to $\mathrm{Ni} 2 \mathrm{p}_{3 / 2}$ and $\mathrm{Ni} 2 \mathrm{p}_{1 / 2}$ of metallic Ni $[42,43]$, while the double peak features at 855.6 and $872.9 \mathrm{eV}$ are characteristic of $\mathrm{Ni}^{2+}$ valence state [44]. In addition, the consecutive shake-up satellite peaks at 861.4 and $880.4 \mathrm{eV}$ are indicative of the magnetic chemical state of $\mathrm{Ni}^{2+}[45]$. 

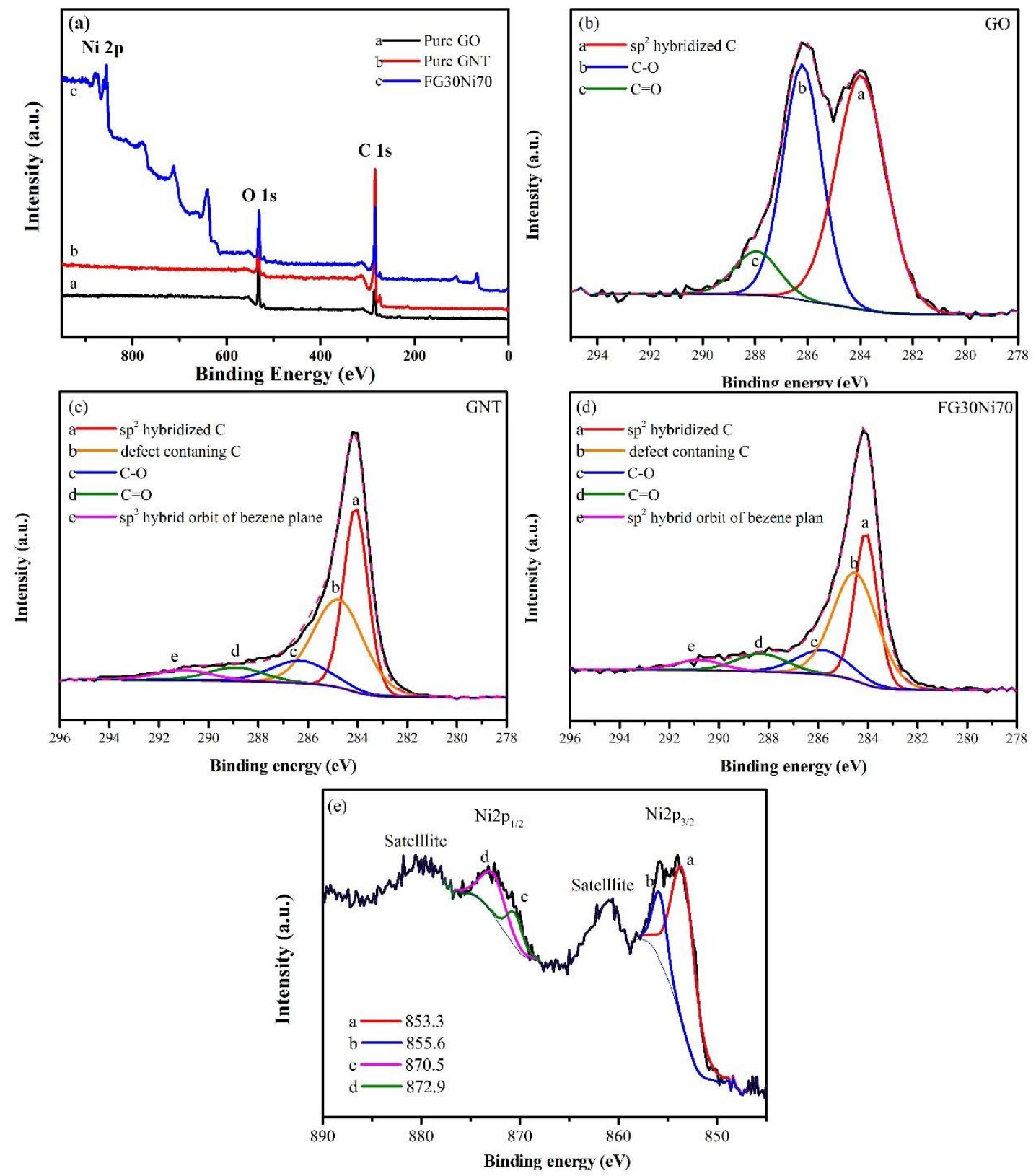

Fig. 4 XPS survey scan spectra of GO, GNTs and FG30Ni70 nanocomposites (a), and C 1s spectra of GO (b), GNT (c) and FG30Ni70 (d), and Ni 2p spectra (e) of FG30Ni70 nanocomposites.

\subsection{Dye removal performance}

The dye removal performance of the products is presented in Fig. 5. Under dark and UV irradiation, the UV-VIS absorbance spectra (take FG30Ni70 nanocomposites as an example) show a maximum absorbance peak at around $554.5 \mathrm{~nm}$ for the RhB solution (Fig. $5 \mathrm{a}$ and b). The initial absorbance is located at around 1.0 a.u., which corresponds to the initial $\mathrm{RhB}$ concentration of $5 \mathrm{ppm}$. The peak decreases dramatically within the first $15 \mathrm{~min}$ and then 
stabilises at an absorbance of around 0.6 a.u. after $30 \mathrm{~min}$, which indicates an equilibrium being reached with the initial $15 \mathrm{~min}$. The removal efficiency of FG30Ni70 under dark is calculated as $34.7 \%$. Under UV light irradiation after $1 \mathrm{~h}$ in dark for equilibrium, the $\mathrm{RhB}$ adsorption results for FGNi nanocomposites are displayed in Fig. 5b. The start point is from 0.6 a.u. which is similar to the equilibrium point in dark, and the absorbance peak of $\mathrm{RhB}$ decreases gradually to 0.15 after exposing under UV light for 120 min irradiation (corresponds to another $73.6 \%$ of removal efficiency after physical adsorption). The RhB reduction at this stage can be regarded as photo-degradation. Meanwhile, there is no obvious wavelength shift for the absorbance peak under UV irradiation. This indicates that there was no $\mathrm{N}$-deethylation of $\mathrm{RhB}$ dye, breaking them into smaller molecules. The $\mathrm{RhB}$ dye was completely removed via physical adsorption rather than being transferred into other byproducts. The time-based adsorption efficiency and total removal efficiency of all samples are displayed in Fig. 5c and d. Under dark condition (Fig. 5c), the removal efficiencies of all samples reach equilibrium within the initial 15 min same as the FG30Ni70 sample which is described in Fig. 5a. However, the removal efficiencies rise with the increased carbon content in the sample (Fig. 5c). As shown in Fig. S5, a small amount of RhB (without nanocomposite) was degraded after $120 \mathrm{~min}$ of UV light irradiation, recorded $12.4 \%$. Nevertheless, the photocatalytic process was clearly observed with the nanocomposites. The removal efficiencies continue to increase, especially for the pure Ni, FG10Ni90, FG30Ni70 and FG50Ni50 samples (Fig. 5d). The results show that the physical adsorption and photodegradation process occurred in all Ni-based samples. It is also interesting to note that the total removal efficiency of FG30Ni70 sample overtook FG50Ni50 after 150 min, indicating a better removal performance. 

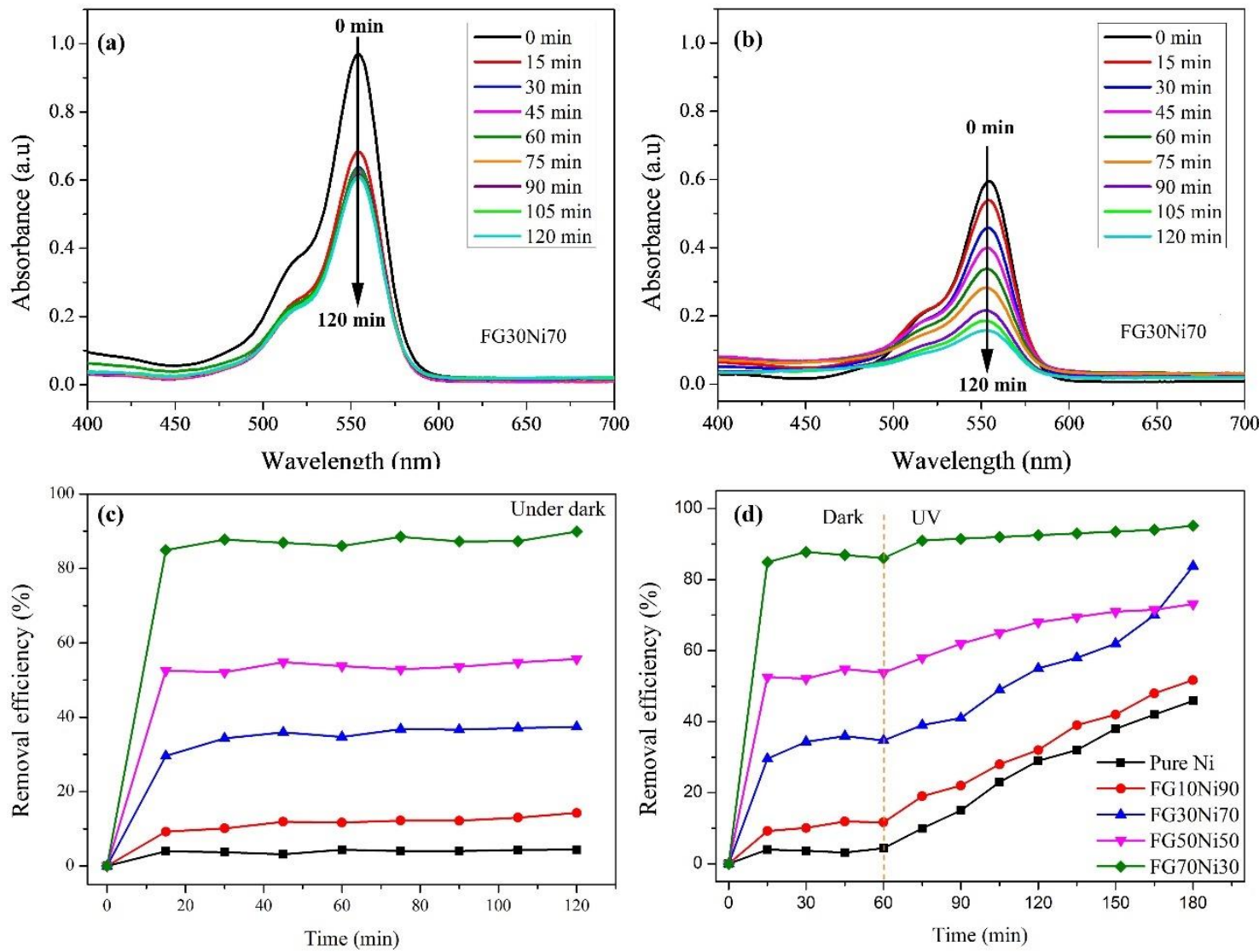

Fig. 5 Time based UV-VIS absorbance spectra of FG30Ni70 nanocomposites (a under dark and b under UV) and time based removal efficiency of all FGNi samples: (c) under dark and (d) dark with UV.

The final removal efficiencies of all samples are summarised in Fig. 6a. Under dark condition (Fig. 6b), the removal efficiency ranges from $4.31 \%$ of pure Ni to $92.8 \%$ of FG70Ni30 sample after $2 \mathrm{~h}$. The amount of $\mathrm{RhB}$ adsorbed by FG70Ni30 nanocomposites reaches as high as $46.3 \mathrm{mg} \mathrm{g}^{-1}$. The removal of the $\mathrm{RhB}$ under dark condition should be attributed to the physical adsorption only. Samples with higher surface areas could absorb more amount of dyes, which is consistent with the BET results (Fig. 2). By subtracting the dark efficiency, the removal efficiency under UV can be obtained as $41.61 \%$ for pure Ni, $40.1 \%$ for FG10Ni90, $49.1 \%$ for FG30Ni70, $19.3 \%$ for FG50Ni50 and $6.81 \%$ for FG70Ni30 as shown in Fig. 6c. Because the initial concentrations for UV degradation, after physical adsorption, are different from sample to sample with different carbon/metal ratios, the degradation efficiency under UV irradiation is calculated by considering the remaining $\mathrm{RhB}$ in solutions as $100 \%$, and the results are presented in Fig. 6d. The histogram shows that the UV degradation efficiency of 
pure Ni, FG10Ni90, FG30Ni70 and FG50Ni50 is $43.5 \%, 47.9 \%, 73.6 \%$ and $65.5 \%$, respectively. It is merely $29.3 \%$ for FG70Ni30, as much less amount of dyes remained after the physical adsorption by the graphene layer like structures. Therefore, although the FG30Ni70 nanocomposites do not display the largest surface area (Fig. 2), it was the optimal proportion between $\mathrm{Ni}$ and carbon components for the best removal performance through a synergistic effect of physical adsorption and photo-degradation. By combining these unique properties, i.e. physical adsorption and photo-degradation, it is possible to prolong the lifespan of carbon-based adsorbent as the adsorbed organic pollutants would decompose into smaller molecules via photocatalytic process under UV irradiation.
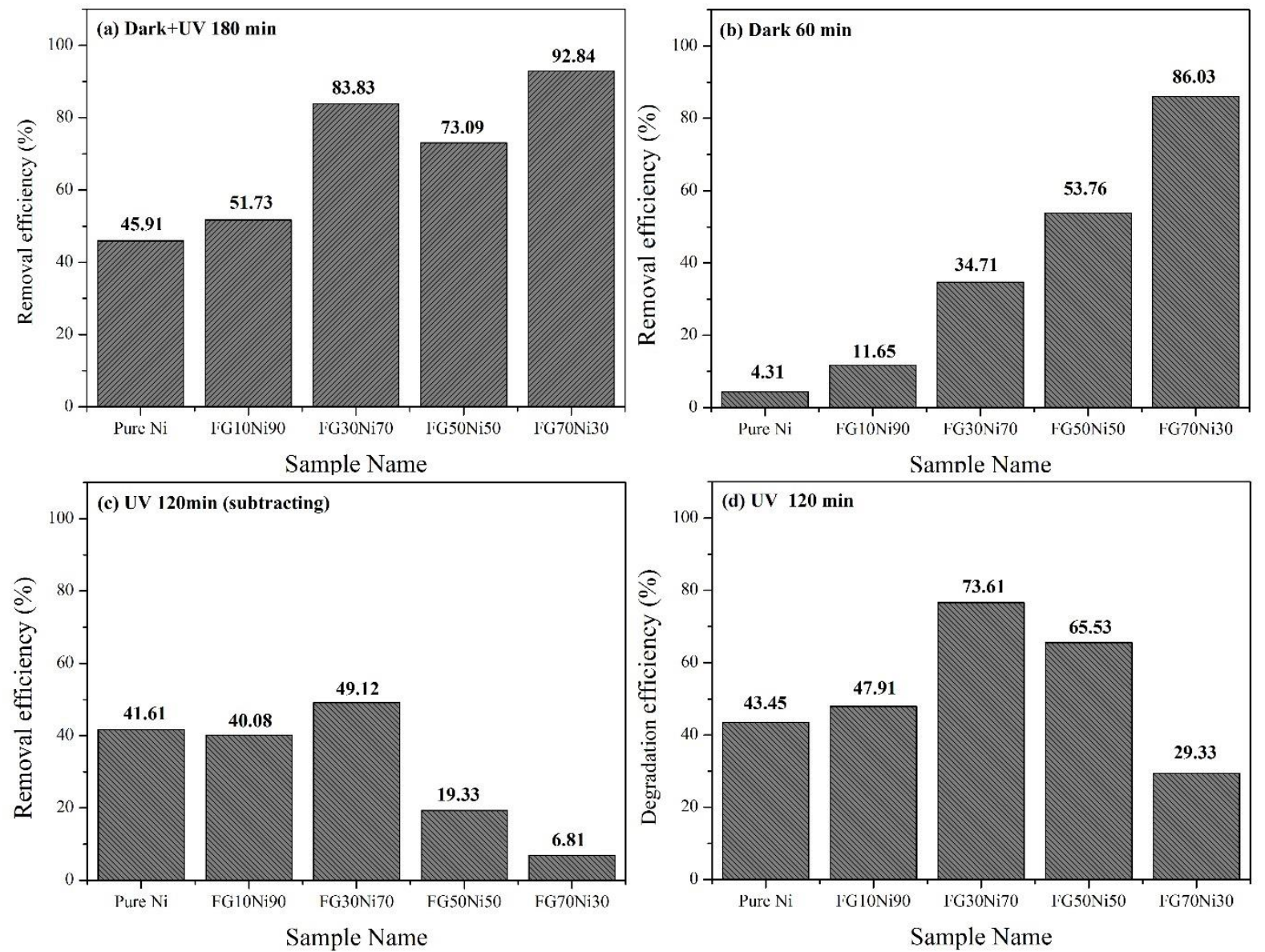

Fig. 6 Removal efficiency of samples under: (a) dark for 60min and UV for 120 min, (b). dark 60 min, (c) UV 120 min (subtracting) and (d) UV $120 \mathrm{~min}$. 


\subsection{The adsorption kinetic discussion}

To assess the effect of different RhB concentrations on the samples, Fig. S6a summarises the removal performance of FG30Ni70 nanocomposites with different RhB concentrations from $1,5,10$ to $15 \mathrm{ppm}$. Although the removal efficiency under dark decreases with the increase of the RhB concentration (Fig. S6b), the calculated adsorption capacity of FG30Ni70 increased from $9.82 \mathrm{mg} \mathrm{g}^{-1}$ in $1 \mathrm{ppm} \mathrm{RhB}$ solution to $24.8 \mathrm{mg} \mathrm{g}^{-1}$ in $15 \mathrm{ppm}$ solution (Fig. S6c). The decrease of the removal percentage of $\mathrm{RhB}$ in solution with increased initial concentration can be ascribed to the saturation of adsorption sites on the nanocomposites [46]. Meanwhile, the increase of total adsorption capacity was caused by the high driving force for mass transfer at high $\mathrm{RhB}$ concentration [47]. Using the pseudo-first-order and pseudo-secondorder models $[12,46]$, the adsorption kinetic study of the physical adsorption process in FG30Ni70 sample was carried out at $5 \mathrm{ppm}$ of $\mathrm{RhB}$ solution under dark.

The pseudo-first-order model could be presented as:

$$
\log \left(q_{e}-q_{t}\right)=\log q_{e}-\frac{k_{1} t}{2.303}
$$

The pseudo-second-order model could be presented as:

$$
\frac{t}{q_{t}}=\frac{1}{k_{2} q_{e}^{2}}+\frac{t}{q_{e}}
$$

where $\mathrm{q}_{\mathrm{e}}$ and $\mathrm{q}_{\mathrm{t}}$ are the amount of $\mathrm{RhB}\left(\mathrm{mg} \mathrm{g}^{-1}\right)$ adsorbed at time $\mathrm{t}$ and at equilibrium, while $\mathrm{k}_{1}$ and $\mathrm{k}_{2}$ are the rate constant of pseudo-first-order adsorption $\left(\mathrm{min}^{-1}\right)$ and pseudo-secondorder adsorption $\left(\mathrm{g} \mathrm{mg}^{-1} \mathrm{~min}^{-1}\right)$. As shown in Fig. 7, the adsorption capacity of FG30Ni70 nanocomposites in 5 ppm solution displays a sharp increase in the initial $10 \mathrm{~min}$, and then back to stable. The capacity reaches $14.6 \mathrm{mg} \mathrm{g}^{-1}$ in $90 \mathrm{~min}$, with a minor increase tendency afterward. The data fitting based on those two kinetic models (blue line for pseudo-first-order and red line for pseudo-second-order) is also shown in Fig. 7. The relevant fitted results 
including correlation coefficients $\left(\mathrm{R}^{2}\right)$ are illustrated in the insert table of Fig. 7. According to the $\mathrm{R}^{2}$ of both models, the pseudo-second-order model shows a better fitting than the pseudofirst-order model, which is 0.9920 to 0.9675 . In the fitted line (Fig. 7), the pseudo-secondorder model also displays a better fitting with experimental data, where the pseudo-first-order model exhibits a flat line after $30 \mathrm{~min}$. It can be concluded that the physical adsorption of RhB with FGNi nanocomposites follows the pseudo-second-order. Meanwhile, the calculated equilibrium adsorption capacity from the pseudo-second-order model $\left(15.5 \mathrm{mg} \mathrm{g}^{-1}\right)$ is also more accurate than the one from the pseudo-first-order model (13.6 $\left.\mathrm{mg} \mathrm{g}^{-1}\right)$ when compared with the experimental data $\left(14.8 \mathrm{mg} \mathrm{g}^{-1}\right)$.

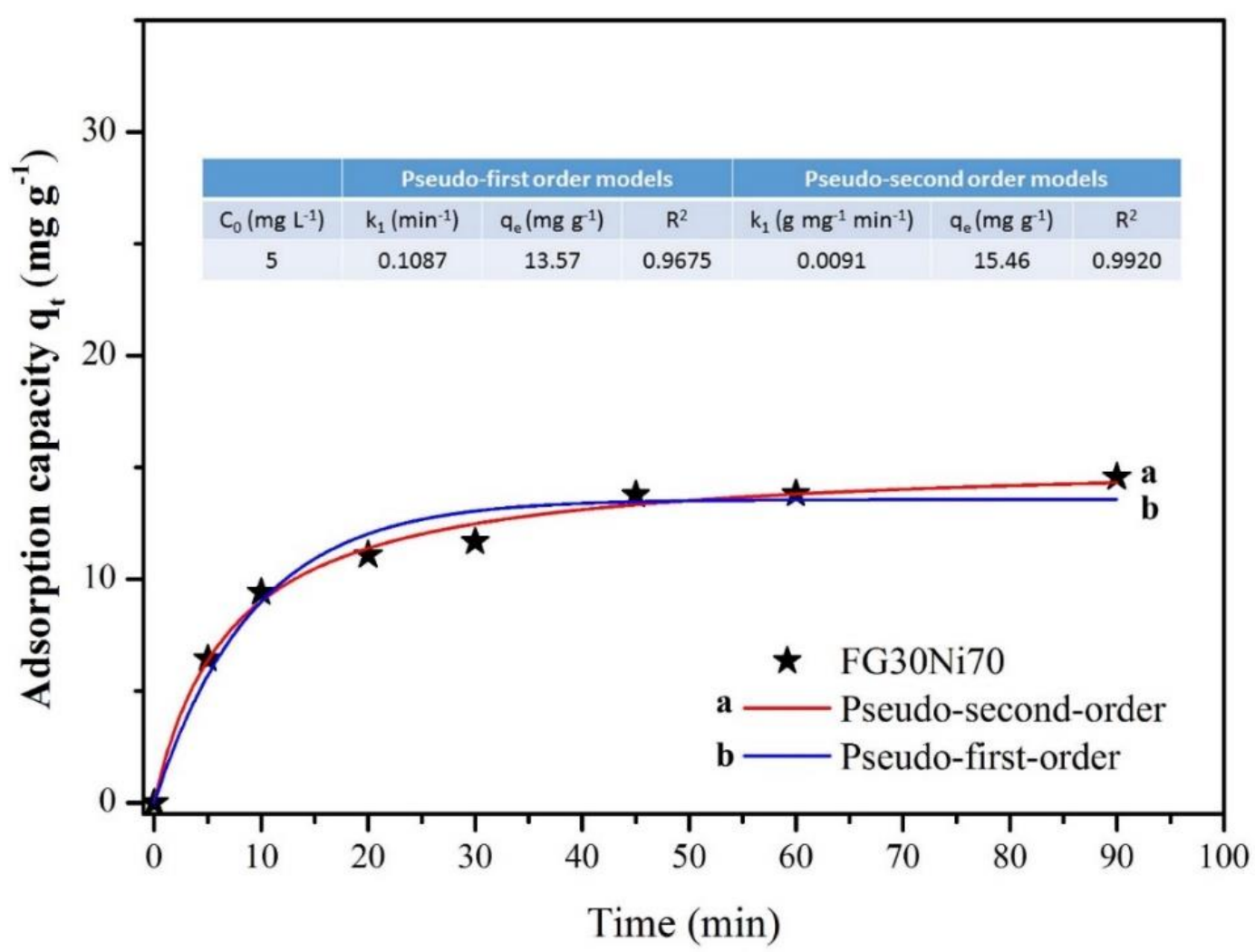

Fig. 7 The kinetic plots of FG30Ni70 nanocomposites in 5 ppm RhB solution, the insert table is the adsorption kinetic parameters fitted by the pseudo-first-order and pseudo-second-order models. 


\subsection{The photo-degradation mechanism discussion}

Under UV irradiation, the as-prepared FGNi nanocomposites (Fig. S6d) exhibit good RhB removal performance, and FG30Ni70 sample shows the best removal ability with a total efficiency of $83.0 \%$ via synergetic physical adsorption and photo-degradation. This could be translated to a removal capacity of around $41.5 \mathrm{mg} \mathrm{g}^{-1}$ in a $5 \mathrm{ppm} \mathrm{RhB}$ solution, precisely. This includes a $34.7 \%$ physical removal under dark and a further $76.3 \%$ photo-degradation for the remained RhB under UV irradiation (Fig. S6d).
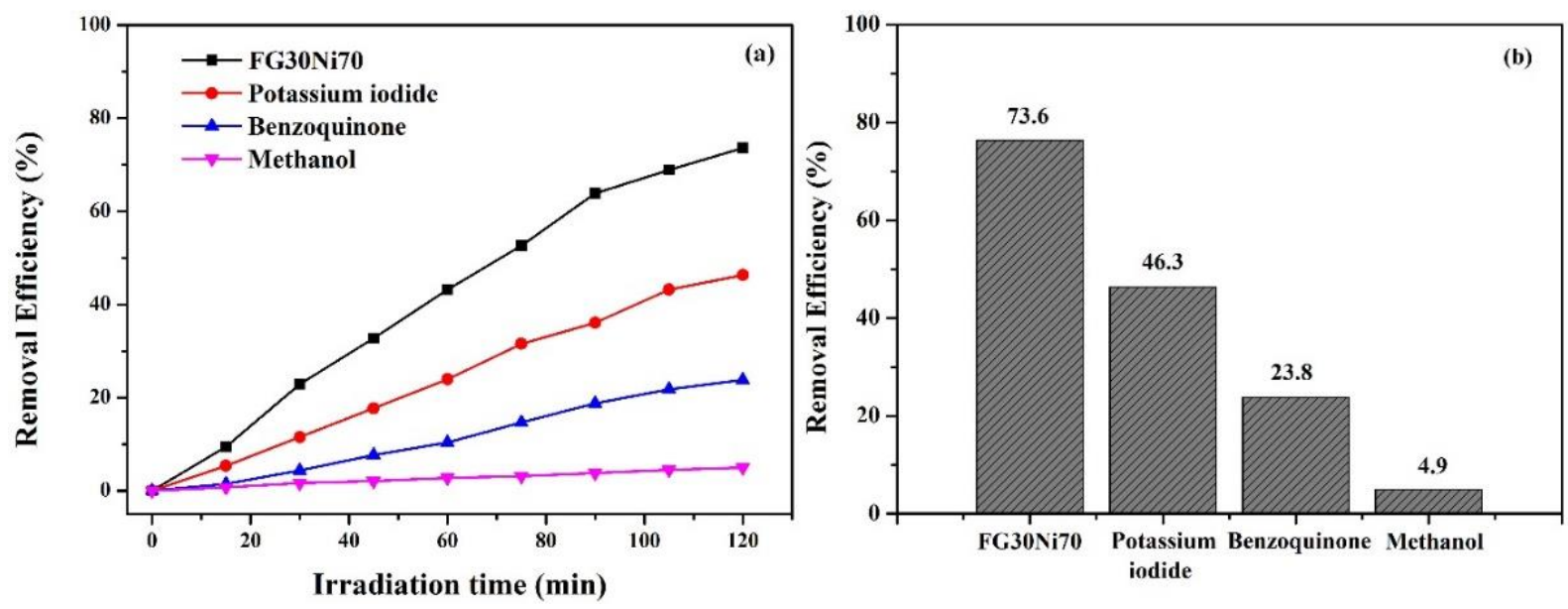

Fig. 8 Photo-degradation efficiency of FG30Ni70 and its species scavenger samples (potassium iodide, pbenzoquinone and methanol): (a) time based curvy and (b) histogram.

To further investigate the photo-degradation mechanism, a scavenger experiment was introduced to clarify the reactions, and the results are displayed in Fig. 8. As can be seen in Fig. 8 b, the degradation efficiency decrease dramatically from $73.6 \%$ of FG30Ni70 to $4.9 \%$ by adding methanol $\left(\mathrm{OH}^{*}\right.$ free radicals), to $23.8 \%$ by adding $\mathrm{BQ}\left(\mathrm{O}_{2}{ }^{-*}\right.$ free radicals $)$ and to $46.3 \%$ by adding potassium iodide $\left(\mathrm{h}^{+}\right.$free radicals). This result has confirmed the involvement of $\mathrm{OH}^{*}$ free radicals as the main reactive species, followed by $\mathrm{O}_{2}{ }^{-*}$ free radicals in the degradation process. The involvement of $\mathrm{h}^{+}$was not as active as $\mathrm{OH}^{-}$free radicals and $\mathrm{O}_{2} *$ free radicals, as the degradation efficiency only decreased to $46.3 \%$ when potassium iodide was added in the scavenger test. The decorated $\mathrm{Ni}$ on this nanocomposite enhanced the 
generation of strong oxidant $\left(\mathrm{OH}^{\cdot}\right.$ free radicals) which was most needed in the photocatalytic work, and a similar result was also reported by Zhao and et al. [48]. Thus, the possible mechanism of the dye degradation with novel Ni decorated carbon composites is proposed in Fig. 9:

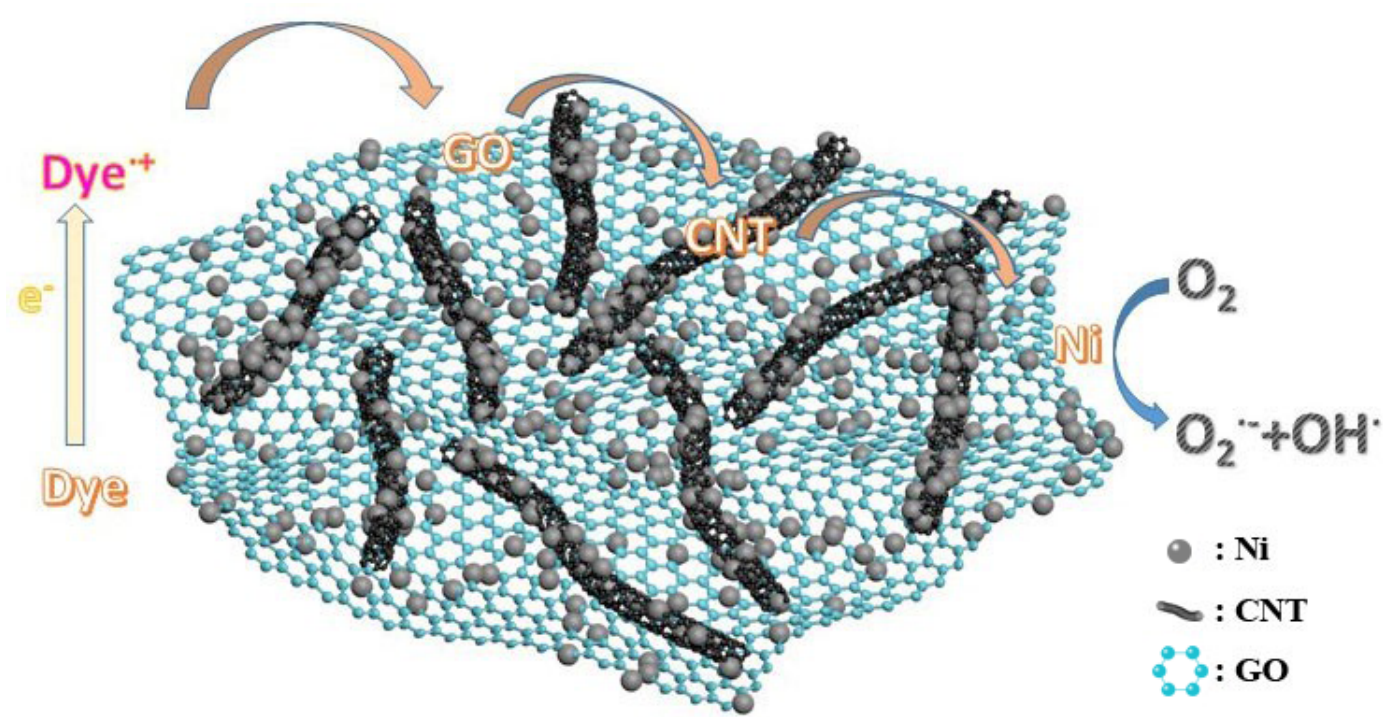

Fig. 9 A proposed schematic of the photocatalytic mechanism with FGNi nanocomposites.

As shown in Reaction (1), it is believed that the electrons can be excited from the dye (i.e. $\mathrm{RhB}^{+}$) and then trapped by the surface absorbed $\mathrm{O}_{2}$ and generated several reactive radicals $[49,50]$. Meanwhile, the electrons injection rate was proved faster in the graphene based materials than that in traditional semiconductors [23, 48], but the faster transfer of electrons may lead to faster recombination of electrons and $\mathrm{RhB}^{\cdot+}$ which resulted in poor degradation performance. However, after the coating of $\mathrm{Ni}$ nanoparticles, due to the higher work function of CNTs and $\mathrm{Ni}(-4.8 \mathrm{eV}$ and $-5.15 \mathrm{eV}$, respectively) which are higher than graphene $(-4.42$ eV) $[23,48]$, it is believed that electrons can be transferred to Ni and CNTs which enhance the separation process of $\mathrm{dye}^{\cdot+}$ and electrons rather than the recombination between them. The electrons are then trapped by surface absorbed $\mathrm{O}_{2}$ to produce $\mathrm{O}_{2}{ }^{*}$ free radicals that would degrade the $\mathrm{RhB}$ dyes as described in Reaction (2), that is the reason why the removal efficiency decreased to $23.2 \%$ after the addition of BQ (Fig. 8). Meanwhile, the more 
dominant degradation process was caused by $\mathrm{OH}^{*}$ free radicals as shown in the scavenger test (Fig. 8). Although the generation of $\mathrm{OH}^{\cdot}$ free radicals is normally occurred through the oxidation of holes as shown in Reaction (3) [6, 32], but not in this case due to the scavenger experiment. Therefore, the generation of $\mathrm{OH}^{\cdot}$ free radicals in this system can be regarded from the oxidation of water molecules by $\mathrm{O}_{2}{ }^{\bullet-}$ free radicals as described in Reaction (4) [14, 51]. That is why the scavenger of either $\mathrm{O}_{2}{ }^{*-}$ or $\mathrm{OH}^{*}$ free radicals would significantly decrease the removal efficiency. Finally, the obtained free radicals then reacted with dyes and produce environmental products (i.e. $\mathrm{H}_{2} \mathrm{O}$ and $\mathrm{CO}_{2}$ ) [49].

$$
\begin{aligned}
& \mathrm{RhB} \rightarrow \mathrm{RhB}^{\cdot+}+\mathrm{e}^{-} \\
& \text {Reaction (1) } \\
& \mathrm{e}^{-}+\mathrm{O}_{2} \rightarrow \mathrm{O}_{2}^{\cdot-} \\
& \text { Reaction (2a) } \\
& \mathrm{O}_{2}{ }^{\cdot-}+\mathrm{RhB}^{+} \rightarrow \text { Degradation products (i.e. } \mathrm{H}_{2} \mathrm{O} \text { and } \mathrm{CO}_{2} \text { ) } \\
& \text { Reaction (2b) } \\
& \mathrm{h}^{+}+\mathrm{OH}^{-} \rightarrow \mathrm{OH}^{-} \\
& \text {Reaction (3) } \\
& \mathrm{e}^{-}+\mathrm{O}_{2} \rightarrow \mathrm{O}_{2}{ }^{-}+\mathrm{e}^{-}+2 \mathrm{H}^{+} \rightarrow \mathrm{H}_{2} \mathrm{O}_{2}+\mathrm{e}^{-} \rightarrow \mathrm{OH}^{-}+\mathrm{OH}^{-} \\
& \text {Reaction (4) } \\
& \mathrm{OH}^{\cdot}+\mathrm{RhB}^{\cdot+} \rightarrow \text { Degradation products (i.e. } \mathrm{H}_{2} \mathrm{O} \text { and } \mathrm{CO}_{2} \text { ), } \\
& \text { Reaction (5) }
\end{aligned}
$$

$\mathrm{Ni}$ or ferrite-based carbon materials were initially adopted as physical adsorbents due to their ferromagnetism which was easily collected, and very few Ni-based products were reported as photocatalytic materials. Based on the $\mathrm{RhB}$ removal performance above, the removal capacity of the sample FG30Ni70 also outperformed them by far. Table 1 presents the comparison of dye removal performance between this work with previous results. In the 3-d hierarchical Ni/C nanocomposites, the products show only $12.5 \mathrm{mg} \mathrm{g}^{-1}$ adsorption capacity even with $10 \mathrm{ppm}$ solution [52], though only physical adsorption was investigated in their study. This figure in FG30Ni70 nanocomposites in this work is $17.4 \mathrm{mg} \mathrm{g}^{-1}$ at $5 \mathrm{ppm}$ and 20.0 $\mathrm{mg} \mathrm{g}^{-1}$ in 10 ppm solution (Fig. S6c). The $\mathrm{Ni@graphene} \mathrm{nanocomposites} \mathrm{only} \mathrm{displayed} \mathrm{the}$ 
adsorption capacity of $4 \mathrm{mg} \mathrm{g}^{-1}$ even under $20 \mathrm{ppm} \mathrm{RhB}$ solution. In the $\mathrm{Ni}$ - carbon shell graphene nanocomposites, the removal capacity of $21.1 \mathrm{mg} \mathrm{g}^{-1}$ was obtained with $5 \mathrm{ppm}$ RhB solution [53], while it is $41.5 \mathrm{mg} \mathrm{g}^{-1}$ for FG30Ni70 nanocomposites in the current study. Meanwhile, the graphene-Au nanocomposites which were adopted as a photocatalytic showed the photo-degradation capacity of $29.7 \mathrm{mg} \mathrm{g}^{-1}$, and this value for the 3D CNTpillared RGO nanostructure (with Ni particles as the catalyst for CNT growing) was around $24.27 \mathrm{mg} \mathrm{g}^{-1}$. Meanwhile, as shown in Fig. S7, the ferromagnetism of Ni nanoparticles coating makes FG30Ni70 nanocomposites easily to be collected after reaction by magnets. Thus, the FGNi nanocomposites through a novel preparation method show great potentials as an efficiency material in removing organic dyes.

Table 1 Comparison of RhB dye removal performance between this work and previous results.

\begin{tabular}{|c|c|c|c|c|}
\hline Samples & $\begin{array}{c}\text { Initial } \\
\text { concentration }\end{array}$ & $\begin{array}{c}\text { Adsorption } \\
\left(\mathbf{m g ~ g}^{-1}\right)\end{array}$ & $\begin{array}{c}\text { Photo-degradation } \\
\left(\mathbf{m g ~ g}^{-\mathbf{1}}\right)\end{array}$ & Reference \\
\hline $\begin{array}{c}\text { 3-d hierarchical Ni/C } \\
\text { nanocomposites }\end{array}$ & $10 \mathrm{ppm}$ & 12.5 & -- & {$[52]$} \\
\hline $\begin{array}{c}\text { Ni@graphene } \\
\text { nanocomposites }\end{array}$ & $20 \mathrm{ppm}$ & 4 & -- & {$[53]$} \\
\hline $\begin{array}{c}\text { Ni - carbon shell - } \\
\text { graphene } \\
\text { nanocomposites }\end{array}$ & $4.79 \mathrm{ppm}$ & 21.1 & -- & {$[48]$} \\
\hline $\begin{array}{c}\text { graphene-gold } \\
\text { nanocomposites }\end{array}$ & $2.5 \mathrm{ppm}$ & & & {$[23]$} \\
\hline $\begin{array}{c}\text { 3D CNT-pillared } \\
\text { RGO nanostructure }\end{array}$ & $2.5 \mathrm{ppm}$ & & 24.2 & This work \\
\hline FG30Ni70 & $5 \mathrm{ppm}$ & & 41.6 & . \\
\hline
\end{tabular}

\section{Conclusions}

In summary, a well-dispersed GNT nanostructure has been prepared through a freeze-drying method and uniformly distributed Ni nanoparticles have been successfully coated onto such GNTs by MLM process and a subsequent reduction method. The obtained products possess a unique structure with a high surface area and exhibit excellent dye removal performance. The $\mathrm{RhB}$ removal test indicated a synergistic effect of physical adsorption and photo-degradation 
under UV irradiation. The FG30Ni70 samples displayed a removal capacity of $41.5 \mathrm{mg} \mathrm{g}^{-1}$ in 5 ppm RhB solution which outperformed most reported $\mathrm{Ni} / \mathrm{C}$ products. Considering the ferromagnetism of Ni nanoparticles, the FGNi nanocomposites are easy to be collected after reaction with dyes by magnetic separation technology. Therefore, the novel FGNi nanocomposites through a facile preparation method show great potentials as an efficient material in removing organic dyes.

\section{Acknowledgments}

This work is supported by a joint Ph.D. scholarship from the China Scholarship Council (CSC) and the University of Nottingham. The authors also would like to acknowledge the technical assistance and instrumentation access from the Nanoscale and Microscale Research Centre (NMRC) in the University of Nottingham.

\section{Declaration of competing interest}

The authors declare that they have no conflict of interest.

\section{References}

[1] L. Yin, Z. Liu, Y. Yang, Y. Guo, G. Zhang, F. Gai, Y. Ao, B. Xin, Y. Liu, Structured carbon fiber clothtemplated ZIF-8 by binder-free method for efficient dyes removal from water, Materials Chemistry and Physics, 242 (2020) 122563.

[2] C. Zhao, J. Guo, Q. Yang, L. Tong, J. Zhang, J. Zhang, C. Gong, J. Zhou, Z. Zhang, Preparation of magnetic Ni@graphene nanocomposites and efficient removal organic dye under assistance of ultrasound, Applied Surface Science, 357 (2015) 22-30.

[3] R. Kumar, S.A. Ansari, M. Barakat, A. Aljaafari, M.H. Cho, A polyaniline@ MoS 2 -based organicinorganic nanohybrid for the removal of Congo red: adsorption kinetic, thermodynamic and isotherm studies, New Journal of Chemistry, 42 (2018) 18802-18809.

[4] S.A. Ansari, R. Kumar, M.A. Barakat, M.H. Cho, Simple and sustainable route for large scale fabrication of few layered molybdenum disulfide sheets towards superior adsorption of the hazardous organic pollutant, Journal of Materials Science: Materials in Electronics, 29 (2018) 7792 7800 .

[5] L. Xia, X. Jiang, Z. Cheng, Y. Liao, Z. Wang, Q. Pu, M. Duan, Synthesis of Pp-16@ Ag/AgCl of high performance photocatalyst particles for decomposition of Rhodamine B and fast green dyes, Materials Chemistry and Physics, 218 (2018) 98-107. 
[6] M.T. Thein, J.E. Chim, S.Y. Pung, Y.F. Pung, Highly UV light driven WOx@ZnO nanocomposites synthesized by liquid impregnation method, Journal of Industrial and Engineering Chemistry, 46 (2017) 119-129.

[7] C. Lee, X. Wei, J.W. Kysar, J. Hone, Measurement of the elastic properties and intrinsic strength of monolayer graphene, Science, 321 (2008) 385-388.

[8] J. Shi, T. Wu, K. Teng, W. Wang, M. Shan, Z. Xu, H. Lv, H. Deng, Simultaneous electrospinning and spraying toward branch-like nanofibrous membranes functionalised with carboxylated MWCNTs for dye removal, Materials Letters, 166 (2016) 26-29.

[9] C. Santhosh, V. Velmurugan, G. Jacob, S.K. Jeong, A.N. Grace, A. Bhatnagar, Role of nanomaterials in water treatment applications: a review, Chemical Engineering Journal, 306 (2016) 1116-1137.

[10] R. Thines, N. Mubarak, S. Nizamuddin, J. Sahu, E. Abdullah, P. Ganesan, Application potential of carbon nanomaterials in water and wastewater treatment: a review, Journal of the Taiwan Institute of Chemical Engineers, 72 (2017) 116-133.

[11] L. Chen, Q. Han, W. Li, Z. Zhou, Z. Fang, Z. Xu, Z. Wang, X. Qian, Three-dimensional graphenebased adsorbents in sewage disposal: a review, Environmental Science and Pollution Research, 25 (2018) 25840-25861.

[12] L. Ai, J. Jiang, Removal of methylene blue from aqueous solution with self-assembled cylindrical graphene-carbon nanotube hybrid, Chemical Engineering Journal, 192 (2012) 156-163.

[13] H. Sun, Z. Xu, C. Gao, Multifunctional, ultra - flyweight, synergistically assembled carbon aerogels, Advanced Materials, 25 (2013) 2554-2560.

[14] L. Jiang, X. Yuan, G. Zeng, Z. Wu, J. Liang, X. Chen, L. Leng, H. Wang, H. Wang, Metal-free efficient photocatalyst for stable visible-light photocatalytic degradation of refractory pollutant, Applied Catalysis B: Environmental, 221 (2018) 715-725.

[15] M. Sabri, A. Habibi-Yangjeh, S. Vadivel, Novel $\mathrm{ZnO} / \mathrm{Ag}_{6} \mathrm{Si}_{2} \mathrm{O}_{7}$ nanocomposites for activation of persulfate ions in photocatalytic removal of organic contaminants under visible light, Materials Chemistry and Physics, 239 (2020) 121988.

[16] Q. Zhang, Z. Lu, S. Jin, Y. Zheng, T. Ye, D. Yang, Y. Li, L. Zhu, L. Zhu, TiO2 nanotube-carbon macroscopic monoliths with multimodal porosity as efficient recyclable photocatalytic adsorbents for water purification, Materials Chemistry and Physics, 173 (2016) 452-459.

[17] H. Yu, X. Huang, P. Wang, J. Yu, Enhanced photoinduced-stability and photocatalytic activity of CdS by dual amorphous cocatalysts: synergistic effect of $\mathrm{Ti}$ (IV)-hole cocatalyst and $\mathrm{Ni}$ (II)-electron cocatalyst, The Journal of Physical Chemistry C, 120 (2016) 3722-3730.

[18] M. Mishra, D.M. Chun, $\alpha-\mathrm{Fe}_{2} \mathrm{O}_{3}$ as a photocatalytic material: A review, Applied Catalysis A: General, 498 (2015) 126-141.

[19] G. Li, J. Hou, W. Zhang, P. Li, G. Liu, Y. Wang, K. Wang, Graphene-bridged $\mathrm{WO}_{3} / \mathrm{MoS}_{2}$ Z-scheme photocatalyst for enhanced photodegradation under visible light irradiation, Materials Chemistry and Physics, 246 (2020) 122827.

[20] S.E.G.D. Rani, A.G. Kumar, S. Steplinpaulselvin, R. Rajaram, T.S. Silambarasan, I.S. Lydia, Y. Chen, Survival assessment of simple food webs for dye wastewater after photocatalytic degradation using $\mathrm{SnO}_{2} / \mathrm{GO}$ nanocomposites under sunlight irradiation, Science of The Total Environment, (2020) 137805.

[21] X. Li, Y. Ma, Z. Yang, D. Huang, S. Xu, T. Wang, Y. Su, N. Hu, Y. Zhang, In situ preparation of magnetic $\mathrm{Ni}$-Au/graphene nanocomposites with electron-enhanced catalytic performance, Journal of Alloys and Compounds, 706 (2017) 377-386.

[22] A. Qusti, R. Mohamed, M.A. Salam, Photocatalytic synthesis of aniline from nitrobenzene using Ag-reduced graphene oxide nanocomposite, Ceramics International, 40 (2014) 5539-5546.

[23] L.L. Zhang, Z. Xiong, X. Zhao, Pillaring chemically exfoliated graphene oxide with carbon nanotubes for photocatalytic degradation of dyes under visible light irradiation, Acs Nano, 4 (2010) 7030-7036. 
[24] S. Bai, X. Shen, X. Zhong, Y. Liu, G. Zhu, X. Xu, K. Chen, One-pot solvothermal preparation of magnetic reduced graphene oxide-ferrite hybrids for organic dye removal, Carbon, 50 (2012) 23372346.

[25] Z.H. Xiao, R. Zhang, X.Y. Chen, X.L. Li, T.F. Zhou, Magnetically recoverable Ni@carbon nanocomposites: Solid-state synthesis and the application as excellent adsorbents for heavy metal ions, Applied Surface Science, 263 (2012) 795-803.

[26] X. Wu, Z. Zhang, C. Xia, B. Chen, X. Jin, Z. Huang, Y.G. Liu, M. Fang, X. Min, Magnetically recoverable Ni@ C composites: The synthesis by carbonization and adsorption for $\mathrm{Fe}^{3+}$, Journal of Alloys and Compounds, 718 (2017) 15-21.

[27] K. Gotoh, T. Kinumoto, E. Fujii, A. Yamamoto, H. Hashimoto, T. Ohkubo, A. Itadani, Y. Kuroda, H. Ishida, Exfoliated graphene sheets decorated with metal/metal oxide nanoparticles: simple preparation from cation exchanged graphite oxide, Carbon, 49 (2011) 1118-1125.

[28] Y. Cao, Q. Su, R. Che, G. Du, B. Xu, One-step chemical vapor synthesis of Ni/graphene nanocomposites with excellent electromagnetic and electrocatalytic properties, Synthetic Metals, 162 (2012) 968-973.

[29] C. Zhou, J. Wang, J.A. Szpunar, X-ray chemical imaging and the electronic structure of a single nanoplatelet Ni/graphene composite, Chemical Communications, 50 (2014) 2282-2285.

[30] S.I. Cha, K.T. Kim, S.N. Arshad, C.B. Mo, S.H. Hong, Extraordinary strengthening effect of carbon nanotubes in metal - matrix nanocomposites processed by molecular - level mixing, Advanced Materials, 17 (2005) 1377-1381.

[31] K. Divya, A. Chandran, V. Reethu, S. Mathew, Enhanced photocatalytic performance of RGO/Ag nanocomposites produced via a facile microwave irradiation for the degradation of Rhodamine $B$ in aqueous solution, Applied Surface Science, 444 (2018) 811-818.

[32] M.T. Thein, S.Y. Pung, A. Aziz, M. Itoh, Effect of Ni coupling on the photoluminescence property and photocatalytic activity of $\mathrm{ZnO}$ nanorods, Journal of the Taiwan Institute of Chemical Engineers, 61 (2016) 156-165.

[33] Y. Zhang, Z. Wang, Y. Ji, S. Liu, T. Zhang, Synthesis of Ag nanoparticle-carbon nanotube-reduced graphene oxide hybrids for highly sensitive non-enzymatic hydrogen peroxide detection, RSC Advances, 5 (2015) 39037-39041.

[34] Y. Zhang, Y. Liu, L. Chen, X. Hu, L. Zhang, L. Hu, Y. Chen, One-dimensional graphene nanoribbons hybridized with carbon nanotubes as cathode and anode interfacial layers for high performance solar cells, RSC Advances, 5 (2015) 49614-49622.

[35] M. Thommes, K. Kaneko, A.V. Neimark, J.P. Olivier, F. Rodriguez-Reinoso, J. Rouquerol, K.S. Sing, Physisorption of gases, with special reference to the evaluation of surface area and pore size distribution (IUPAC Technical Report), Pure and Applied Chemistry, 87 (2015) 1051-1069.

[36] D. Li, M.B. Müller, S. Gilje, R.B. Kaner, G.G. Wallace, Processable aqueous dispersions of graphene nanosheets, Nature nanotechnology, 3 (2008) 101.

[37] F. Li, Y. Guo, Y. Liu, H. Qiu, X. Sun, W. Wang, Y. Liu, J. Gao, Fabrication of Pt-Cu/RGO hybrids and their electrochemical performance for the oxidation of methanol and formic acid in acid media, Carbon, 64 (2013) 11-19.

[38] L. Dong, W. Chen, C. Zheng, N. Deng, Microstructure and properties characterization of tungsten-copper composite materials doped with graphene, Journal of Alloys and Compounds, 695 (2017) 1637-1646.

[39] H. Wang, K. Zhu, L. Yan, C. Wei, Y. Zhang, C. Gong, J. Guo, J. Zhang, D. Zhang, J. Zhang, Efficient and scalable high-quality graphene nanodot fabrication through confined lattice plane electrochemical exfoliation, Chemical Communications, 55 (2019) 5805-5808.

[40] J. Yu, T. Ma, S. Liu, Enhanced photocatalytic activity of mesoporous $\mathrm{TiO}_{2}$ aggregates by embedding carbon nanotubes as electron-transfer channel, Physical Chemistry Chemical Physics, 13 (2011) 3491-3501. 
[41] J. Li, S. Tang, L. Lu, H.C. Zeng, Preparation of nanocomposites of metals, metal oxides, and carbon nanotubes via self-assembly, Journal of the American Chemical Society, 129 (2007) 94019409.

[42] S. Dutta, A. Indra, Y. Feng, T. Song, U. Paik, Self-supported nickel iron layered double hydroxidenickel selenide electrocatalyst for superior water splitting activity, ACS applied materials \& interfaces, 9 (2017) 33766-33774.

[43] M.C. Biesinger, B.P. Payne, L.W. Lau, A. Gerson, R.S.C. Smart, X - ray photoelectron spectroscopic chemical state quantification of mixed nickel metal, oxide and hydroxide systems, Surface and Interface Analysis: An International Journal devoted to the development and application of techniques for the analysis of surfaces, interfaces and thin films, 41 (2009) 324-332.

[44] P. Dubey, N. Kaurav, R.S. Devan, G. Okram, Y. Kuo, The effect of stoichiometry on the structural, thermal and electronic properties of thermally decomposed nickel oxide, RSC advances, 8 (2018) 5882-5890.

[45] M. Chhetri, S. Sultan, C. Rao, Electrocatalytic hydrogen evolution reaction activity comparable to platinum exhibited by the $\mathrm{Ni} / \mathrm{Ni}(\mathrm{OH})_{2} /$ graphite electrode, Proceedings of the National Academy of Sciences, 114 (2017) 8986-8990.

[46] M.T. Yagub, T.K. Sen, S. Afroze, H.M. Ang, Dye and its removal from aqueous solution by adsorption: a review, Advances in colloid and interface science, 209 (2014) 172-184.

[47] Y. Bulut, H. Aydın, A kinetics and thermodynamics study of methylene blue adsorption on wheat shells, Desalination, 194 (2006) 259-267.

[48] Z. Xiong, L.L. Zhang, J. Ma, X. Zhao, Photocatalytic degradation of dyes over graphene-gold nanocomposites under visible light irradiation, Chemical Communications, 46 (2010) 6099-6101.

[49] T. Wu, G. Liu, J. Zhao, H. Hidaka, N. Serpone, Photoassisted degradation of dye pollutants. V. Self-photosensitized oxidative transformation of rhodamine $B$ under visible light irradiation in aqueous $\mathrm{TiO}_{2}$ dispersions, The Journal of Physical Chemistry B, 102 (1998) 5845-5851.

[50] P.V. Kamat, Photochemistry on nonreactive and reactive (semiconductor) surfaces, Chemical Reviews, 93 (1993) 267-300.

[51] F. Soofivand, M. Salavati-Niasari, Step synthesis and photocatalytic activity of NiO/graphene nanocomposite under UV and visible light as an effective photocatalyst, Journal of Photochemistry and Photobiology A: Chemistry, 337 (2017) 44-53.

[52] Y. Song, T. Qiang, M. Ye, Q. Ma, Z. Fang, Metal organic framework derived magnetically separable 3-dimensional hierarchical Ni@C nanocomposites: Synthesis and adsorption properties, Applied Surface Science, 359 (2015) 834-840.

[53] H. Du, Z. Wang, Y. Chen, Y. Liu, Y. Liu, B. Li, X. Wang, H. Cao, Anchoring superparamagnetic coreshells onto reduced graphene oxide: fabrication of $\mathrm{Ni}$-carbon-rGO nanocomposite for effective adsorption and separation, RSC Advances, 5 (2015) 10033-10039. 